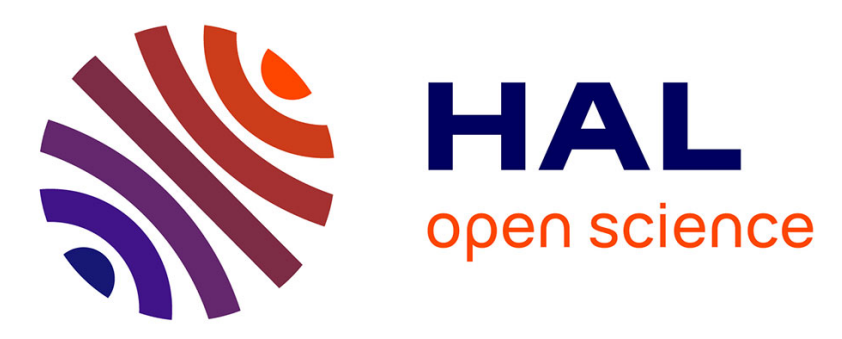

\title{
The ARESC study: an international survey on the antimicrobial resistance of pathogens involved in uncomplicated urinary tract infections
}

Gian Carlo Schito, Kurt G. Naber, Henry Botto, Juan Palou, Teresita Mazzei, Laura Gualco, Anna Marchese

\section{To cite this version:}

Gian Carlo Schito, Kurt G. Naber, Henry Botto, Juan Palou, Teresita Mazzei, et al.. The ARESC study: an international survey on the antimicrobial resistance of pathogens involved in uncomplicated urinary tract infections. International Journal of Antimicrobial Agents, 2009, 34 (5), pp.407. 10.1016/j.ijantimicag.2009.04.012 . hal-00556347

\section{HAL Id: hal-00556347 https://hal.science/hal-00556347}

Submitted on 16 Jan 2011

HAL is a multi-disciplinary open access archive for the deposit and dissemination of scientific research documents, whether they are published or not. The documents may come from teaching and research institutions in France or abroad, or from public or private research centers.
L'archive ouverte pluridisciplinaire HAL, est destinée au dépôt et à la diffusion de documents scientifiques de niveau recherche, publiés ou non, émanant des établissements d'enseignement et de recherche français ou étrangers, des laboratoires publics ou privés. 


\section{Accepted Manuscript}

Title: The ARESC study: an international survey on the antimicrobial resistance of pathogens involved in uncomplicated urinary tract infections

Authors: Gian Carlo Schito, Kurt G. Naber, Henry Botto, Juan Palou, Teresita Mazzei, Laura Gualco, Anna Marchese

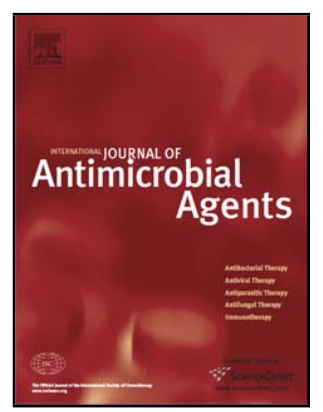

PII:

DOI:

Reference:

S0924-8579(09)00214-3

ANTAGE 3040

To appear in: International Journal of Antimicrobial Agents

Received date: $\quad$ 26-3-2009

Revised date: $\quad 8-4-2009$

Accepted date: $\quad$ 9-4-2009

Please cite this article as: Schito GC, Naber KG, Botto H, Palou J, Mazzei T, Gualco L, Marchese A, The ARESC study: an international survey on the antimicrobial resistance of pathogens involved in uncomplicated urinary tract infections, International Journal of Antimicrobial Agents (2008), doi:10.1016/j.ijantimicag.2009.04.012

This is a PDF file of an unedited manuscript that has been accepted for publication. As a service to our customers we are providing this early version of the manuscript. The manuscript will undergo copyediting, typesetting, and review of the resulting proof before it is published in its final form. Please note that during the production process errors may be discovered which could affect the content, and all legal disclaimers that apply to the journal pertain. 
The ARESC study: an international survey on the antimicrobial resistance of pathogens involved in uncomplicated urinary tract infections

Gian Carlo Schito ${ }^{a, *}$, Kurt G. Naber ${ }^{b}$, Henry Botto ${ }^{c}$, Juan Palou ${ }^{d}$, Teresita Mazzei ${ }^{e}$, Laura Gualco ${ }^{a}$, Anna Marchese ${ }^{a}$

a Sezione di Microbiologia del DISCMIT, University of Genoa, Genoa, Italy

${ }^{\mathrm{b}}$ Technical University of Munich, Munich, Germany

${ }^{\mathrm{c}}$ Department of Urology, Hôpital Foch, Suresnes, France

${ }^{d}$ Fundació Puigvert, Autonomous University of Barcelona, Barcelona, Spain

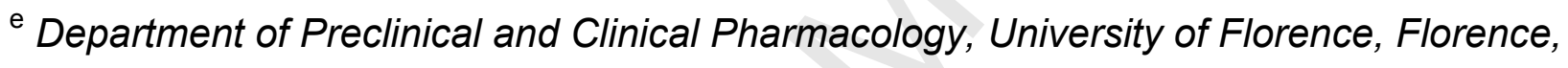
Italy

ARTICLE INFO

Article history:

Received 26 March 2009

Accepted 9 April 2009

Keywords:

Escherichia coli

Cystitis

Fosfomycin

Ciprofloxacin

Amoxicillin/clavulanic acid 
* Corresponding author. Tel.:+39 010353 7660; fax: +39 0103537651.

E-mail address: giancarlo.schito@unige.it (G.C. Schito). 


\section{ABSTRACT}

The ARESC (Antimicrobial Resistance Epidemiological Survey on Cystitis) study is an international survey to investigate the prevalence and susceptibility of pathogens causing cystitis. Female patients $(N=4264)$ aged $18-65$ years with symptoms of uncomplicated cystitis were consecutively enrolled in nine European countries as well as Brazil during 2003-2006. Pathogens were identified and their susceptibility to nine antimicrobials was determined. Escherichia coli accounted for $76.7 \%$ of isolates. Among E. coli, $10.3 \%$ of the isolates were resistant to at last three different classes of antimicrobial agents. Resistance was most common to ampicillin (48.3\%), trimethoprim/sulfamethoxazole $(29.4 \%)$ and nalidixic acid (18.6\%). Fosfomycin, mecillinam and nitrofurantoin were the most active drugs (98.1\%, $95.8 \%$ and $95.2 \%$ susceptible strains, respectively) followed by ciprofloxacin, amoxicillin/clavulanic acid and cefuroxime $(91.7 \%, 82.5 \%$ and $82.4 \%$, respectively). Resistance to ciprofloxacin was $>10 \%$ in Brazil, Spain, Italy and Russia. Overall, Proteus mirabilis were more susceptible to $\beta$-lactams and less susceptible to non$\beta$-lactams than E. coli, whereas Klebsiella pneumoniae strains, which are intrinsically resistant to ampicillin, were less susceptible to mecillinam (88.8\%), fosfomycin (87.9\%), cefuroxime $(78.6 \%)$ and nitrofurantoin (17.7\%). Resistance was rare in Staphylococcus saprophyticus, with the exception of ampicillin (36.4\%) and trimethoprim/sulfamethoxazole (10.2\%). In Italy, Spain, Brazil and Russia, the countries most affected by antimicrobial resistance, extended-spectrum $\beta$-lactamase (ESBL) enzymes (mainly CTX-M type) were detected in 48 strains (39 E. coli, 6 K. pneumoniae and 3 P. mirabilis). Despite wide intercountry variability in bacterial susceptibility rates to the other antimicrobials tested, fosfomycin and mecillinam have preserved their in vitro activity in all countries investigated against the most common uropathogens. 


\section{Introduction}

Uncomplicated urinary tract infections (UTIs) are among the most prevalent infectious diseases and affect mainly women. Between one-quarter and one-half of all women experience a UTI during their lifetime [1].

The overall aetiology has not changed in recent years and Escherichia coli remains by far the most common uropathogen, accounting for $>80 \%$ of all positive cultures [2]. However, the management of these infections, generally treated empirically, is becoming complicated due to the emergence of resistance to several first-line antimicrobial agents in this primary pathogen [3].

Because there is a close correlation between resistance to antibiotics and the persistence of $E$. coli in UTIs as well as wide local variations in the susceptibility of uropathogens to these drugs, recommendation of first-line treatment agents should be supported by updated epidemiological data $[4,5]$.

The ARESC (Antimicrobial Resistance Epidemiological Survey on Cystitis) study was conducted in nine countries in Europe as well as Brazil from September 2003 to June 2006 to determine the susceptibility of the major uropathogens circulating in the community of these geographic areas.

Part of the ARESC data focusing on E. coli, with emphasis on the clinical implications of the study for empirical antimicrobial therapy, has recently been published [5]. In the present paper we report the complete set of microbiological results involving all bacterial pathogens isolated from uncomplicated cystitis. 


\section{Materials and methods}

\subsection{Collaborating centres}

Seventy centres were enrolled over a 3-year period (2003-2006) in nine European countries and Brazil. Sixty-two centres (3 Austria, 6 Brazil, 10 France, 7 Germany, 4 Hungary, 5 Italy, 6 Poland, 10 Russia, 9 Spain and 2 The Netherlands) provided valuable strains. All participating laboratories adopted the same protocol for classifying urine samples as positive and negative in accordance with the Infectious Diseases Society of America (IDSA) guidelines [6].

Each local site forwarded the strains isolated to the central laboratory (DISCMIT, Microbiology Section, University of Genoa, Italy) by courier, where the pathogens were reidentified and stored at $-70^{\circ} \mathrm{C}$ until susceptibility tests were performed.

\subsection{Patients}

This was a prospective, multicentre, multinational, observational epidemiological survey. Written consent was obtained from all patients.

Healthy women between 18 years and 65 years of age with symptoms of uncomplicated lower UTI were eligible for inclusion. Detailed inclusion/exclusion criteria have been reported previously [5]. Briefly, besides women with uncomplicated cystitis, patients with recurrent UTI ( $\geq 3$ episodes in the last year) as well as pregnant and diabetic women were included. Patients with upper UTI, concomitant or prophylactic antimicrobial treatment 
within 15 days before inclusion in the study, history of renal impairment, and anatomical and functional urinary tract abnormalities were excluded.

\subsection{Bacteria}

All strains isolated $(N=3018)$ were identified by local laboratories employing their routine methods and were re-identified by the central laboratory using the API system (bioMérieux, Milan, Italy).

\subsection{Susceptibility testing}

All bacteria were assayed against the following antimicrobial agents: ampicillin; amoxicillin/clavulanic acid; cefuroxime; ciprofloxacin; trimethoprim/sulfamethoxazole; fosfomycin; mecillinam; nalidixic acid; and nitrofurantoin. The compounds were obtained from their respective manufacturers or from commercial sources. The minimal inhibitory concentrations (MICs) of the antimicrobials were assessed by the broth microdilution method in cation-adjusted Mueller-Hinton broth as suggested by the Clinical and Laboratory Standards Institute (CLSI) [7]. The MICs of mecillinam and fosfomycin were determined by the agar dilution method in Mueller-Hinton agar, supplemented with glucose-6-phosphate at a concentration of $25 \mathrm{mg} / \mathrm{L}$ when fosfomycin was studied. Escherichia coli ATCC 25922 was included in each run as a control.

Strains were defined as susceptible, intermediate-resistant or resistant according to CLSI recommendations [7]. To determine susceptibility/resistance rates for the whole spectrum of uropathogens isolated, E. coli breakpoints were used for all organisms when specific figures were not available. 
Multiresistance was defined as simultaneous lack of susceptibility to at least three different classes of antimicrobial agents.

Cross-resistance was defined as resistance to two or more antimicrobial agents within the same class of antibiotics and was considered to be due to a common genetic mechanism. Associated resistance was defined as resistance to two or more antimicrobial agents of different drug classes and was considered to be due to unrelated mechanisms.

The double-disk synergy test to detect extended-spectrum $\beta$-lactamase (ESBL)-producing E. coli, Klebsiella pneumoniae and Proteus mirabilis strains was performed as a standard disk diffusion assay on Mueller-Hinton agar (Oxoid, Milan, Italy).

Disks containing aztreonam, ceftazidime, cefepime, ceftriaxone and cefotaxime (30 $\mu \mathrm{g}$ each) were placed at a $30 \mathrm{~mm}$ distance (centre-to-centre) around a disk containing amoxicillin $(20 \mu \mathrm{g})$ plus clavulanic acid $(10 \mu \mathrm{g})$. Enhancement of the inhibition zone towards the amoxicillin + clavulanic acid disk, indicating synergy between clavulanic acid and any one of the test antibiotics, was taken as presumptive evidence of ESBL production. The synergistic activity of clavulanic acid with both ceftazidime and cefotaxime was confirmed by means of Etest strips (AB BIODISK, Solna, Sweden) containing ceftazidime/ceftazidime plus clavulanic acid and cefotaxime/cefotaxime plus clavulanic acid. Production of ESBL was assumed when clavulanic acid caused at least three twofold decreases in the MICs of the abovementioned antimicrobial agents. 


\subsection{Molecular characterisation of extended-spectrum $\beta$-lactamase determinants}

The 51 phenotypic putative ESBL-producers and their transconjugants were screened for the presence of bla $a_{\mathrm{TEM}}$, bla $\mathrm{SHV}_{\mathrm{SH}}$ and bla CTX-M $_{\mathrm{M}}$ genes by polymerase chain reaction (PCR) using primers and conditions described previously [8].

\subsection{Statistical analysis}

Statistical analysis was performed using Fisher's exact test and $\chi^{2}$ test. The threshold for statistical significance was $P<0.001$.

\section{Results}

Between September 2003 and June 2006, 4264 eligible patients aged 18-65 years with symptoms of acute uncomplicated UTI were enrolled in the survey. Uropathogens with colony counts of $>10^{4} / \mathrm{mL}$ were cultured from 3181 patients $(74.6 \%)$. In 3060 patients $(96.2 \%)$ the infection was monomicrobial and a mixed infection was found in 121 patients (3.8\%).

Of the 3181 patients with bacteriuria, causative agents $(n=3018)$ from 2927 patients were sent to the central laboratory for further evaluation.

Among the organisms cultured, E. coli was the predominant pathogen (2315/3018;

$76.7 \%$ ), ranging from $68.1 \%$ in Austria to $83.8 \%$ in France (Table 1), followed by

Staphylococcus saprophyticus (108/3018; 3.6\%), K. pneumoniae (107/3018; 3.5\%) and $P$. mirabilis (104/3018; 3.4\%). Other Enterobacteriaceae (Enterobacter spp., Citrobacter spp., Serratia spp., Klebsiella spp., Pantoea spp., Salmonella spp., Morganella morganii and 
Hafnia alvei) were responsible for only $2.9 \%$ of infections. The number of non-

Enterobacteriaceae isolated was very limited, and in particular in this group only six strains of Pseudomonas aeruginosa were found ( $0.2 \%)$. All other species represented $<7 \%$ of the isolates (Table 1).

Infections caused by K. pneumoniae appeared to be most common in Brazil (6.1\%), Austria and Italy (both 5.5\%), whilst S. saprophyticus was more frequently responsible of UTIs in The Netherlands and Brazil (5.6\% and $4.9 \%$, respectively). In contrast, infections due to K. pneumoniae were seldom encountered in France (1.0\%), whilst in Hungary and Italy no isolate of $S$. saprophyticus was found.

Proteus mirabilis was significantly more common in the elderly (>50 years) $(P<0.001)$, whilst S. saprophyticus was mostly recovered from younger patients ( $<30$ years) $(P<$ 0.001) (data not shown).

Table 2 shows the susceptibility patterns of all E. coli strains analysed. Globally, fosfomycin and mecillinam emerged as the most active drugs tested $(98.1 \%$ and $95.8 \%$ susceptible strains, respectively) followed by nitrofurantoin (95.2\%) and ciprofloxacin (91.7\%). Ampicillin and trimethoprim/sulfamethoxazole were active against a reduced number of isolates ( $45.1 \%$ and $70.6 \%$ susceptible strains, respectively). Almost $20 \%$ of all E. coli had reduced susceptibility to amoxicillin/clavulanic acid, cefuroxime and nalidixic acid.

Not all sites had the same susceptibility profile, with some countries being less affected by resistance problems than others (Table 3). For instance, in France only the activity of ampicillin was dramatically reduced (60.9\% susceptible strains). 
In Germany, Hungary, Poland and The Netherlands, $>90 \%$ of the strains were susceptible to fosfomycin, mecillinam, nitrofurantoin and ciprofloxacin. The susceptibility rates varied widely between countries for ampicillin (32.7-65.5\%), amoxicillin/clavulanic acid (51.993.5\%), cefuroxime (73.0-93.0\%) and trimethoprim/sulfamethoxazole (54.5-87.8\%).

For Italy, Spain and Russia, only fosfomycin, mecillinam and nitrofurantoin were characterised by percentages of susceptibility $>90 \%$. Resistance rates to ciprofloxacin exceeded $10 \%$. In Italy and Spain, ampicillin, trimethoprim/sulfamethoxazole, cefuroxime and amoxicillin/clavulanic acid were all characterised by susceptibility rates $\leq 80.9 \%$.

The MIC distributions of all antibiotics tested for each country were also analysed. The highest MIC of fosfomycin was $512 \mathrm{mg} / \mathrm{L}$ (one strain isolated in Spain), whilst the highest MIC value of nitrofurantoin was $256 \mathrm{mg} / \mathrm{L}$ and was observed for strains isolated in Brazil, Germany, Russia and Spain. Cefuroxime MIC values $>128 \mathrm{mg} / \mathrm{L}$ were recorded in Brazil, France, Italy, Russia and Spain. Amoxicillin/clavulanic acid MICs reached $128 \mathrm{mg} / \mathrm{L}$ in Brazil, France, Hungary, Italy, Poland and Spain. For the other drugs, the ranges of MIC values did not vary greatly among different countries (data not shown).

Resistance to any agent was associated with increased resistance to the other agents tested. The only exception was the absence of an association between fosfomycin and ciprofloxacin resistance. The difference in the rate of ciprofloxacin resistance between fosfomycin-resistant and -susceptible $E$. coli was not statistically significant $(P=0.5)$. Of 2315 E. coli isolates from 10 countries, less than one-half were fully susceptible to the agents investigated $(850 / 2315 ; 36.7 \%)$. Overall, 458 isolates $(19.8 \%)$ were resistant only to one agent, which was most commonly either ampicillin (13.6\%) or 
trimethoprim/sulfamethoxazole (2.8\%), and $228(9.8 \%)$ were resistant to two antimicrobials, generally represented by ampicillin and trimethoprim/sulfamethoxazole (7.3\%). Multiresistance (resistance to at least three different classes of antimicrobial agents) was observed in 239 (10.3\%) of 2315 isolates (data not shown).

The resistance pattern ampicillin/trimethoprim/sulfamethoxazole was the most represented (333/2315; $14.4 \%)$, followed by the profile ampicillin/nalidixic acid/trimethoprim/sulfamethoxazole (6.8\% of the total isolates) (data not shown).

Resistance to cephalosporins, as measured by cefuroxime testing, was seen in 55 of the E. coli isolates. Thirty-nine E. coli strains were ESBL-positive by the double-disk synergy test and quantitative Etest. Molecular characterisation by PCR showed that of the 39 putative ESBL-producers (and their transconjugants), 28 carried a bla CTX-M $_{\text {gene, }} 7$ a blasHV gene and 4 a blaTEM gene. The remaining 16 cefuroxime-resistant strains were found to be also cefoxitin-resistant (data not shown).

Although not statistically significant, with the exception of ciprofloxacin $(P<0.001)$, the percentages of antimicrobial resistance were generally higher among isolates recovered from patients suffering from recurrent UTIs (Table 4).

Despite the large number of patients enrolled in this study, the number of isolates of species other than E. coli did not permit country-wise analysis of the data. Table 5 shows the overall antimicrobial resistance in K. pneumoniae, P. mirabilis and S. saprophyticus.

Against K. pneumoniae, which is intrinsically resistant to ampicillin, amoxicillin/clavulanic acid and ciprofloxacin showed susceptibility percentages $>90 \%$. For fosfomycin and 
mecillinam ca. $88 \%$ of the strains were susceptible, whilst nitrofurantoin was characterised by the lowest percentage of susceptible strains (18\%). Approximately $80 \%$ of the $K$. pneumoniae isolates were susceptible to nalidixic acid and trimethoprim/sulfamethoxazole. As expected, nitrofurantoin was not active against $P$. mirabilis. Fosfomycin and mecillinam inhibited $>85 \%$ of these isolates. Remarkable is the high trimethoprim/sulfamethoxazole, ampicillin and nalidixic acid resistance (>20\%) in P. mirabilis. By the same token, the first two drugs had the lowest rates of susceptibility in S. saprophyticus.

Resistance to cefuroxime was seen in $6.5 \%$ and $4.8 \%$ of $K$. pneumoniae and $P$. mirabilis isolates, most of which produced ESBLs. Molecular characterisation by PCR of these last strains and of their transconjugants showed that all the $P$. mirabilis isolates carried a

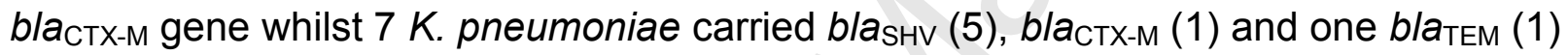
genes.

\section{Discussion}

Uncomplicated cystitis in females is among the most frequent infections in the community. The ARESC study has assessed the epidemiology and susceptibility patterns of common uropathogens to standard antimicrobials used in the treatment of uncomplicated lower UTI (cystitis). The clinical implications for empirical antimicrobial therapy in nine European countries and Brazil have been published elsewhere [5].

Adoption of the same strict criteria to enrol patients and to classify microbiological infection in all 62 centres as well as the uniformity of the method employed for identification to species level and susceptibility testing in a single laboratory guarantee homogeneity and validity to the results. 
As far as the aetiology of UTIs is concerned, as expected E. coli was the most prevalent pathogen (on average $76.7 \%$ ), ranging from $68.1 \%$ in Austria to $83.8 \%$ in France. These data agree with the range $(70-95 \%)$ reported in the literature $[4,9,10]$.

Among countries enrolling a large number of patients, non-E. coli infections appeared to be most common in Italy and Russia (both $27.4 \%$ ). For Russia, the high incidence of nonE. coli uropathogens could be ascribed to the high percentage of patients (33.7\%) suffering from recurrent UTIs recruited in the study.

Staphylococcus saprophyticus was isolated more frequently among young women $(<30$ years) than in older ones and was not found in Italy and Hungary, confirming that the occurrence of this pathogen is strongly influenced by the age of the patient, geographic location and seasonality [11]. As expected, P. mirabilis, K. pneumoniae and other Enterobacteriaceae species were recovered more frequently in patients with recurrent UTI.

Classification of susceptibility/resistance depends on the breakpoints adopted and these may vary in different systems. Using the MIC values reported here, the results can be adjusted to any interpretive local system. In this study, CLSI methodologies and breakpoints were employed for comparing results from different countries.

In each single nation, ampicillin and trimethoprim/sulfamethoxazole were the least active antimicrobial agents against $E$. coli, whilst fosfomycin was the most active drug in terms of susceptible strains, followed by mecillinam and nitrofurantoin. This scenario has already been observed worldwide during recent years. It is alarming that ciprofloxacin-resistant 
strains have been isolated from all countries participating into the study, reaching $>10 \%$ in Italy, Spain, Russia and Brazil.

In comparison with the ECO.SENS survey that explored the period January 1999December 2000 in 17 European countries [10], the ARESC study shows for some countries increased figures of resistance to ampicillin, trimethoprim/sulfamethoxazole, nalidixic acid and ciprofloxacin in $E$. coli and the emergence of ciprofloxacin resistance in Austria. Although two different methods and interpretive criteria were used, this trend of increasing resistance seems real. For Italy, a country that did not participate into the ECO.SENS survey, previous local data are in agreement with the results of the present study [12].

A significant increase in antibiotic resistance in all the countries participating in the ARESC study has also been recorded during the same period (2003-2006) by the European Antimicrobial Resistance Surveillance System (EARSS) network (http://www.rivm.nl/earss) among invasive isolates of $E$. coli, with the exception of Russia and Brazil (these countries were not included in the EARSS network). As expected, the rates of antibiotic resistance observed among nosocomial invasive isolates were higher than those observed in our study, but the 'ranking order' of the countries is similar. Moreover, with Russia and Brazil, comparison of the ARESC data with those of two previous multicentre studies focused on uncomplicated community-acquired UTIs (UTIAP 1998-2001 and a part of the SENTRY Antimicrobial Surveillance Program 2003, respectively) showed a substantial increase in resistance to $\beta$-lactams, trimethoprim/sulfamethoxazole, nitrofurantoin and quinolones $[13,14]$ 
A further threat is represented by the fact that $E$. coli strains circulating in the community are often multiresistant and can carry ESBL genes, a feature that has been confirmed by our data (of the tested microorganisms, $>10 \%$ were in fact multiresistant and $1.7 \%$ produced ESBLs). ESBL production was also observed in $K$. pneumoniae (5.6\%) and $P$. mirabilis (2.9\%) [15-17].

This negative trend has been directly linked to the different use of the antimicrobial agents in diverse geographic areas [18]. Antibiotics employed specifically in UTIs (fosfomycin, mecillinam and nitrofurantoin) exhibited low levels of resistance in all participating countries both in recurrent and non-recurrent UTIs, whilst drugs broadly prescribed for several types of infections seemingly select resistant mutants more easily.

Associated resistance involving $\beta$-lactams, trimethoprim/sulfamethoxazole and fluoroquinolones is common in our collection of strains. Similar associated resistance patterns were observed by Kahlmeter and Menday [19] in the isolates of the ECO.SENS study. This phenotype is selected for not only by the use of quinolones but also by the use of ampicillin, amoxicillin, trimethoprim/sulfamethoxazole and sulfamethoxazole. However, it is reassuring that fosfomycin is active against urinary $E$. coli irrespective of other resistance traits $[15,20,21]$, a notion confirmed by our data. The emergence and dissemination of antibiotic-resistant $E$. coli might be the result not only of the selection of different mutant strains generated by local antimicrobial prescription habits but alternatively or concomitantly by clonal spread.

Some authors have in fact emphasised that the introduction of drug-resistant $E$. coli clonal strains into a community plays a greater role in changing the prevalence of drug-resistant UTIs than the usage of drugs or the prescribing habits in that community $[17,22]$. 
It has also been shown that certain clonal groups of trimethoprim/sulfamethoxazoleresistant and/or ampicillin-resistant $E$. coli (i.e. 'clonal group A' and E. coli $\mathrm{O} 15: \mathrm{K} 52: \mathrm{H} 1$ ) as well as CTX-M ESBL-producers have spread intercontinentally [23-25].

We did not evaluate clonal relationship among trimethoprim/sulfamethoxazole- and/or ampicillin-resistant strains but, in another contribution from this laboratory, we have demonstrated that ca. $50 \%$ of the ARESC ciprofloxacin-resistant $E$. coli strains belong to two international virulent clones (E. coli O15:K52:H1 and O25:H4-ST131) [26]. Both the rates and quality of antimicrobial agent consumption and clonal spread have therefore contributed to the present scenario, at least in some European countries such Italy and Spain.

Conversely, fosfomycin-resistant $E$. coli displayed heterogeneous biotypes and antibiotypes, suggesting no clonal expansion for strains carrying this character.

In conclusion, the resistance patterns of E. coli strains causing uncomplicated UTIs may vary considerably among different countries. As a consequence, no general recommendations are applicable in the absence of laboratory guidance in single patients. Particularly for fluoroquinolones and $\beta$-lactams, the availability of local epidemiological data is mandatory for initiating correct empirical therapy. Fluoroquinolone resistance is an increasing problem in some countries and may worsen because of clonal spread and selection of resistant mutants that can occur readily given the high rate of circulating nalidixic acid-resistant strains. These considerations strengthen the recommendation to employ as first-line agents, when a diagnosis of uncomplicated UTI in a female patient is firmly based, those antibiotics that, because of their use limited to the therapy of this 
condition, suffer very limited rates of resistance and have therefore a superior chance in microbiological terms to eradicate the infection.

Acknowledgments: This study was performed under the auspices of the European Society for Infection in Urology (ESIU) (Chairman: Truls E. Bjerklund-Johansen) affiliated to the European Association of Urology (EAU). The authors are grateful to Antonio Colantoni for statistical evaluation as well as the investigators of the ARESC Study Group who contributed their findings to the study: Austria: Andreas Sommerhuber (Linz), Daniela Ullisch (Wien), Andreas Szalay (Wien); Brazil: Sergio Cimerman (Sao Paulo), Juvencio Jose Dualibe Furtado (Sao Paulo), Reginaldo Guedes Coelho Lopes (Sao Paulo), Mozar De Castro Neto (Belo Horizonte), Jose Maria Cardoso Salles (Belem), Helio Vasconcellos Lopes (Sao Paulo); France: Dutilleul Patrick (Le Cailar), Isabelle Cibois-Honnorat (Mirabeau), Pierre Triot (Arras), Jacques Allix (Rennes), Gilles Sorbe (La Rochelle), Michèle Pithon (Hyeres), Pierre Causse (Saint Etienne), Nathan Abenhaim (Strasbourg), Francois Lacoin (Albens), Jean-Yves Vogel (Husseren-Wesserling); Germany: Thorsten Bruns (Hamburg), Florian M.E. Wagenlehner (Straubing), Andreas Clad (Freiburg), Klaus Buerger (Munich), Christoph Antwerpen (Eggenfelden), Klaus Ruediger (Freiburg), Orlin Savov (Nuremberg); Hungary: Imre Romics (Budapest), Laszlo Pajor (Szeged), Istvan Csaba (Gyula), Peter Tenke (Budapest); Italy: Gianfranco Scarselli (Florence), Gian Luca Bracco (Florence), Aldo Tosto (Florence), Fulvio Zullo (Catanzaro), Salvatore Corsello (Paternò), Piero Bonifazi (Foligno), Cesarina Cecchini (Foligno), Roberto Equinozzi (Foligno); The Netherlands: Alfred Sachs (Utrecht), Ysbrand Stoutenbeek (Utrecht); Poland: Ireneusz Szymczyk (Katowice), Elzbieta Mizgala (Zabrze), Dorota Frydryszczak (Wroclaw), Krzysztof Buczkowski (Bydgoszcz), Bozena Bielak (Lublin), Slawomir Chlabicz (Bialystok); Russia: Oleg Apolikchin Oleg (Moscow), Oleg Loran (Moscow), Andrey V. Zaitsev (Moscow), Vladimir Rafalski (Smolensk), Dimitry Bochkarev (Volgograd), Mikchail 
Kogan (Rostov), Asya Ponomareva (Krasnodar), Vladimir Zuravlev (Ekaterinburg), Sergey

Gorelo (Saint Petersburg), Valentin N. Krupin (Novgorod); Spain: Juan Palou Redorta

(Barcelona), Carles Pigrau (Barcelona), Antoni Gelabert (Barcelona), Javier Angulo

Cuesta (Madrid), Nacho Alós Cortès (Madrid), Remigio Vela Navarrete (Madrid), Manolo de la Rosa Fraile (Granada), Luis Rodriguez (Cabuenes de Gijón), Antonio Marqués Queimadelos (Santiago de Compostela).

Funding: The study was supported by a research grant from Zambon S.p.A., Bresso (MI), Italy.

Competing interests: GCS: Bayer, investigator, speaker at scientific meetings; sanofiaventis, investigator, speaker at scientific meetings; Zambon, investigator, speaker at scientific meetings; Wyeth, investigator; and Angelini, investigator, speaker at scientific meetings. KGN: Bayer, investigator, speaker at scientific meetings; Bionorica, investigator, consultant; Eumedica Pharmaceuticals, consultant; MerLion Pharmaceuticals, investigator, consultant; Daiichi, speaker at scientific meetings, scientific publication; MUCOS Pharma, consultant, speaker at scientific meetings; NanoVibronix, consultant; Ocean Spray Cranberries, investigator; OM Pharma, investigator, consultant; Peninsula/Johnson \& Johnson/Janssen-Cilag, investigator, speaker at scientific meetings; Pharmatoka, investigator, consultant; Polyphor, consultant; Protez, consultant; Rosen Pharma, consultant; sanofi-aventis, investigator, speaker at scientific meetings, scientific publication; UroVision, investigator; and Zambon, investigator, speaker at scientific meetings. HB: Pharmatoka, consultant, investigator. JP: Sanofi-Pasteur, consultant, speaker at scientific meetings; Lilly, consultant, investigator; Amgen, consultant; and Zambon, investigator. TM: Angelini, speaker at scientific meetings, scientific publication; GlaxoSmithKline, speaker at scientific meetings; Janssen-Cilag, consultant; Merck Sharp 
\& Dohme, speaker at scientific meetings; Novartis, speaker at scientific meetings; Pfizer, speaker at scientific meetings, scientific publication; sanofi-aventis, consultant, speaker at scientific meetings; Scharper, scientific publication; Schering-Plough, speaker at scientific meetings; Wyeth, speaker at scientific meetings, scientific publication; and Zambon, investigator, consultant, speaker at scientific meetings. All other authors have no competing interests to declare.

Ethical approval: The protocol of the ARESC study was first approved by a central ethical committee (Bayerische Landesärztekammer, Munich, Germany, No. 03172) and then by the respective local ethical committees. The study complies with the Declaration of Helsinki. The study complies with the Declaration of Helsinki (Edinburgh, Scotland, 2000), Good Clinical Practice (GCP) and the applicable regulatory requirements. 


\section{References}

[1] Grabe M, Bishop MC, Bjerklund-Johansen TE, Botto H, Çek M, Lobel B, et al. EAU guidelines for the management of urinary and male genital tract infections. Urinary Tract Infection (UTI) Working Group of the Health Care Office (HCO) of the European Association of Urology (EAU). Arnhem, The Netherlands: EAU; 2006. http://www.uroweb.org [accessed 10 December 2008].

[2] Kahlmeter G. An international survey of the antimicrobial susceptibility of pathogens from uncomplicated urinary tract infections: the ECO.SENS Project. J Antimicrob Chemother 2003;51:69-76.

[3] Hooton TM, Besser R, Foxman B, Fritsche TR, Nicolle LE. Acute uncomplicated cystitis in an era of increasing antibiotic resistance: a proposed approach to empirical therapy. Clin Infect Dis 2004;39:75-80.

[4] Raz R, Chazan B, Kennes Y, Colodner R, Rottensterich E, Dan M, et al. Empiric use of trimethoprim-sulfamethoxazole (TMP-SMX) in the treatment of women with uncomplicated urinary tract infections, in a geographical area with high prevalence of TMP-SMX-resistant uropathogens. Clin Infect Dis 2002;34:1165-9.

[5] Naber KG, Schito G, Botto H, Palou J, Mazzei T. Surveillance study in Europe and Brazil on clinical aspects and antimicrobial resistance epidemiology in females with cystitis (ARESC): implications for empiric therapy. Eur Urol 2008;54:1164-78.

[6] Rubin RH, Shapiro ED, Andriole VT, Davis RJ, Stamm WE. Evaluation of new antiinfective drugs for the treatment of urinary tract infection. Infectious Diseases Society of America and the Food and Drug Administration. Clin Infect Dis 1992;15(Suppl 1):S216-27. 
[7] Clinical and Laboratory Standards Institute. Methods for dilution antimicrobial susceptibility tests for bacteria that grow aerobically. 7th ed. Approved standard M7-A7. Wayne, PA: CLSI; 2006.

[8] Mugnaioli C, Luzzaro F, De Luca F, Brigante G, Perilli M, Amicosante G, et al. CTX-Mtype extended-spectrum $\beta$-lactamases in Italy: molecular epidemiology of an emerging countrywide problem. Antimicrob Agents Chemother 2006;50:2700-6.

[9] Naber KG, Bergman B, Bishop MC, Bjerklund-Johansen TE, Botto H, Lobel B, et al. EAU guidelines for the management of urinary and male genital tract infections. Urinary Tract Infection (UTI) Working Group of the Health Care Office (HCO) of the European Association of Urology (EAU). Eur Urol 2001;40:576-88.

[10] Kahlmeter G. Prevalence and antimicrobial susceptibility of pathogens in uncomplicated cystitis in Europe. The ECO.SENS study. Int J Antimicrob Agents 2003;22(Suppl 2):49-52.

[11] Raz R, Colodner R, Kunin CM. Who are you-Staphylococcus saprophyticus? Clin Infect Dis 2005;40:896-8.

[12] Fadda G, Nicoletti G, Schito GC, Tempera G. Antimicrobial susceptibility patterns of contemporary pathogens from uncomplicated urinary tract infections isolated in a multicenter Italian survey: possible impact on guidelines. J Chemother 2005;17:251-7.

[13] Stratchounski LS, Rafalski VV. Antimicrobial susceptibility of pathogens isolated from adult patients with uncomplicated community-acquired urinary tract infections in the Russian Federation: two multicentre studies, UTIAP-1 and UTIAP-2. Int J Antimicrob Agents 2006;28(Suppl 1):S4-9.

[14] Andrade SS, Sader HS, Jones RN, Pereira AS, Pignatari AC, Gales AC. Increased resistance to first-line agents among bacterial pathogens isolated from urinary tract infections in Latin America: time for local guidelines? Mem Inst Oswaldo Cruz 2006;101:741-8. 
[15] Karlowsky JA, Hoban DJ, Decorby MR, Laing NM, Zhanel GG. Fluoroquinoloneresistant urinary isolates of Escherichia coli from outpatients are frequently multidrug resistant: results from the North American Urinary Tract Infection Collaborative Alliance-Quinolone Resistance study. Antimicrob Agents Chemother 2006;50:2251-4.

[16] Bonnet R. Growing group of extended-spectrum $\beta$-lactamases: the CTX-M enzymes. Antimicrob Agents Chemother 2004;48:1-14.

[17] Colodner R, Rock W, Chazan B, Keller N, Guy N, Sakran W, et al. Risk factors for the development of extended-spectrum $\beta$-lactamase-producing bacteria in nonhospitalized patients. Eur J Clin Microbiol Infect Dis 2004;23:163-7.

[18] Goossens H, Ferech M, Vander Stichele R, Elseviers M; ESAC Project Group. Outpatient antibiotic use in Europe and association with resistance: a cross-national database study. Lancet 2005;365:579-87.

[19] Kahlmeter G, Menday P. Cross-resistance and associated resistance in 2478 Escherichia coli isolates from the Pan-European ECO-SENS Project surveying the antimicrobial susceptibility of pathogens from uncomplicated urinary tract infections. J Antimicrob Chemother 2003;52:128-31.

[20] Ho PL, Wong RC, Yip KS, Loke SL, Leung MS, Mak GC, et al. Antimicrobial resistance in Escherichia coli outpatient urinary isolates from women: emerging multidrug resistance phenotypes. Diagn Microbiol Infect Dis 2007;59:439-45.

[21] Ungheri D, Albini E, Belluco G. In vitro susceptibility of quinolone-resistant clinical isolates of Escherichia coli to fosfomycin trometamol. J Chemother 2002;14:237-40.

[22] Smith SP, Manges AR, Riley LW. Temporal changes in the prevalence of community-acquired antimicrobial-resistant urinary tract infection affected by Escherichia coli clonal group composition. Clin Infect Dis 2008;46:689-95. 
[23] Manges AR, Johnson JR, Foxman B, O'Bryan TT, Fullerton KE, Riley LW.

Widespread distribution of urinary tract infections caused by a multidrug-resistant Escherichia coli clonal group. N Engl J Med 2001;345:1007-13.

[24] Prats G, Navarro F, Mirelis B, Dalmau D, Margall N, Coll P, et al. Escherichia coli serotype O15:K52:H1 as a uropathogenic clone. J Clin Microbiol 2000;38:201-9.

[25] Nicolas-Chanoine MH, Blanco J, Leflon-Guibout V, Demarty R, Alonso MP, Caniça MM, et al. Intercontinental emergence of Escherichia coli clone O25:H4-ST131 producing CTX-M-15. J Antimicrob Chemother 2008;61:273-81.

[26] Cagnacci S, Gualco L, Debbia E, Schito GC, Marchese A. European emergence of ciprofloxacin-resistant Escherichia coli clonal groups O25:H4-ST 131 and O15:K52:H1 causing community-acquired uncomplicated cystitis. J Clin Microbiol 2008;46:2605-12. 


\section{Table 1}

Distribution of pathogens by country

\begin{tabular}{|c|c|c|c|c|c|c|c|}
\hline \multirow[t]{2}{*}{ Country } & \multicolumn{7}{|c|}{ Pathogens $[n(\%)]$} \\
\hline & Total & $\begin{array}{l}\text { Escherichia } \\
\text { coli }\end{array}$ & $\begin{array}{l}\text { Klebsiella } \\
\text { pneumoniae }\end{array}$ & $\begin{array}{l}\text { Proteus } \\
\text { mirabilis }\end{array}$ & $\begin{array}{l}\text { Staphylococcus } \\
\text { saprophyticus }\end{array}$ & $\begin{array}{l}\text { Other } \\
\text { uropathogens }\end{array}$ & Others \\
\hline Austria & $91(3.0)$ & $62(68.1)$ & $5(5.5)$ & $3(3.3)$ & $2(2.2)$ & $12(13.2)$ & $7(7.7)$ \\
\hline Brazil & $\begin{array}{l}506 \\
(16.8)\end{array}$ & $374(73.9)$ & $31(6.1)$ & $19(3.8)$ & $25(4.9)$ & $32(6.3)$ & $25(4.9)$ \\
\hline France & $\begin{array}{l}488 \\
(16.2)\end{array}$ & 409 (83.8) & $5(1.0)$ & $15(3.1)$ & $21(4.3)$ & $21(4.3)$ & $17(3.5)$ \\
\hline Germany & $\begin{array}{l}317 \\
(10.5)\end{array}$ & $243(76.7)$ & $8(2.5)$ & $15(4.7)$ & $9(2.8)$ & $19(6.0)$ & $23(7.3)$ \\
\hline Hungary & $66(2.2)$ & $52(78.8)$ & $2(3.0)$ & $0(0)$ & $0(0)$ & $10(15.2)$ & $2(3.0)$ \\
\hline Italy & $\begin{array}{l}329 \\
(10.9)\end{array}$ & $239(72.6)$ & $18(5.5)$ & $10(3.0)$ & $0(0)$ & $44(13.4)$ & $18(5.5)$ \\
\hline Poland & $\begin{array}{l}119 \\
(3.9)\end{array}$ & 90 (75.6) & $3(2.5)$ & $4(3.4)$ & $5(4.2)$ & $6(5.0)$ & $11(9.2)$ \\
\hline Russia & $\begin{array}{l}416 \\
(13.8)\end{array}$ & $302(72.6)$ & $19(4.6)$ & $10(2.4)$ & $15(3.6)$ & $46(11.1)$ & $24(5.8)$ \\
\hline Spain & $\begin{array}{l}650 \\
(21.5)\end{array}$ & $515(79.2)$ & $15(2.3)$ & $28(4.3)$ & $29(4.5)$ & $38(5.9)$ & $25(3.8)$ \\
\hline
\end{tabular}




\begin{tabular}{lllllrr}
\hline The & $36(1.2)$ & $29(80.6)$ & $1(2.8)$ & $0(0)$ & $2(5.6)$ & $2(5.6)$ \\
$\begin{array}{l}\text { Netherlands } \\
\text { Total }\end{array}$ & 3018 & $2315(76.7)$ & $107(3.5)$ & $104(3.4)$ & $108(3.6)$ & $230(7.6)$ \\
\end{tabular}

${ }^{a}$ Other Enterobacteriaceae (Enterobacter spp., Citrobacter spp., Serratia spp., Klebsiella spp., Pantoea spp., Salmonella spp.,

Morganella morganii and Hafnia alvei); non-Enterobacteriaceae (Pseudomonas aeruginosa and Burkholderia cepacia); and other

Gram-positive bacteria (Enterococcus faecalis, Enterococcus faecium and Enterococcus spp.).

b Staphylococcus aureus, coagulase-negative staphylococci other than S. saprophyticus and Streptococcus spp. 


\section{Table 2}

Susceptibility pattern of 2315 Escherichia coli isolated from urinary tract infections

\begin{tabular}{|c|c|c|c|c|c|c|}
\hline \multirow[t]{2}{*}{ Antimicrobial agent } & \multicolumn{3}{|l|}{$\mathrm{MIC}(\mathrm{mg} / \mathrm{L})$} & \multicolumn{3}{|c|}{ Susceptibility [\% (no. of strains)] } \\
\hline & Range & $\mathrm{MIC}_{50}$ & $\mathrm{MIC}_{90}$ & $\mathrm{~S}$ & I & $\mathrm{R}$ \\
\hline Ampicillin & 0.25 to $>128$ & 16 & $>128$ & $45.1(1045)$ & $6.6(153)$ & $48.3(1117)$ \\
\hline AMC & $0.25 / 0.12$ to $>128 / 64$ & $8 / 4$ & $16 / 8$ & $82.5(1910)$ & $13.7(316)$ & $3.8(89)$ \\
\hline Mecillinam $^{a}$ & $<0.12$ to $>128$ & 0.25 & 2 & $95.8(2215)$ & $1.5(34)$ & $2.8(64)$ \\
\hline Cefuroxime & $<0.12$ to $>128$ & 4 & 8 & $82.4(1907)$ & $15.2(353)$ & $2.4(55)$ \\
\hline Nalidixic acid & $<0.012$ to $>128$ & 4 & $>128$ & $81.4(1885)$ & $-{ }^{d}$ & $18.6(430)$ \\
\hline Ciprofloxacin $^{\text {b }}$ & $<0.015-64$ & $<0.015$ & 1 & $91.7(2120)$ & $0.2(5)$ & $8.1(187)$ \\
\hline $\mathrm{SXT}{ }^{\mathrm{c}}$ & $<0.015 / 0.30$ to $>16 / 304$ & $0.25 / 4.75$ & $>16 / 304$ & $70.6(1633)$ & $-{ }^{d}$ & $29.4(681)$ \\
\hline Nitrofurantoin & $<0.5-16$ & 16 & 32 & $95.2(2205)$ & $3.1(72)$ & $1.6(38)$ \\
\hline Fosfomycin & $<1-512$ & 2 & 8 & $98.1(2272)$ & $1.3(30)$ & $0.6(13)$ \\
\hline
\end{tabular}

MIC, minimal inhibitory concentration; $\mathrm{MIC}_{50 / 90}$, MIC for $50 \%$ and $90 \%$ of the organisms, respectively; S, susceptible; I, intermediate;

$\mathrm{R}$, resistant; AMC, amoxicillin/clavulanic acid; SXT, trimethoprim/sulfamethoxazole.

a 2313 strains assayed.

${ }^{b} 2312$ strains assayed.

c 2314 strains assayed.

${ }^{\mathrm{d}}$ MIC value for intermediate category does not exist. 


\section{Table 3}

Susceptibility pattern of 2315 Escherichia coli isolated from different countries to various antimicrobial agents

\begin{tabular}{|c|c|c|c|c|c|c|c|c|c|c|c|c|c|c|c|c|c|c|c|c|c|c|c|c|c|c|c|}
\hline \multirow[t]{3}{*}{ Country } & \multicolumn{27}{|c|}{ Susceptibility (\%) } \\
\hline & \multicolumn{3}{|c|}{ AMP } & \multicolumn{3}{|c|}{ AMC } & \multicolumn{3}{|c|}{ MEC } & \multicolumn{2}{|c|}{ CFX } & \multicolumn{3}{|c|}{ NAL } & \multicolumn{3}{|c|}{ CIP } & \multicolumn{4}{|c|}{ SXT } & \multicolumn{2}{|l|}{ NIT } & \multicolumn{4}{|c|}{ FOS } \\
\hline & $\mathrm{S}$ & $\mathrm{I}$ & $\mathrm{R}$ & $\mathrm{S}$ & $\mathrm{I}$ & $\mathrm{R}$ & $\mathrm{S}$ & I & $\mathrm{R}$ & $\mathrm{S}$ & I & $\mathrm{R}$ & $\mathrm{S}$ & I & $\mathrm{R}$ & $\mathrm{S}$ & I & $\mathrm{R}$ & $\mathrm{S}$ & $\mathrm{I}$ & $\mathrm{R}$ & $\mathrm{S}$ & I & $\mathrm{R}$ & $\mathrm{S}$ & $\mathrm{I}$ & $\mathrm{R}$ \\
\hline Austria & 43.5 & 8.2 & 48.3 & 93.5 & 4.9 & 1.6 & 100 & 0 & 0 & 77.4 & 21.0 & 1.6 & 91.9 & $\begin{array}{r}- \\
\end{array}$ & 8.1 & 98.4 & 0 & 1.6 & 71.0 & $\begin{array}{r}- \\
a\end{array}$ & 29.0 & 100 & 0 & 0 & 100 & 0 & 0 \\
\hline Brazil & 37.7 & 5.9 & 56.4 & 79.8 & 14.7 & 5.5 & 94.8 & 1.3 & 3.9 & 74.5 & 22.1 & 3.4 & 75.4 & - & 24.6 & 89.2 & 0 & 10.8 & 54.5 & & 45.5 & 94.3 & 3.3 & 2.4 & 97.1 & 2.1 & 0.8 \\
\hline France & 60.9 & 3.7 & 35.4 & 90.9 & 7.7 & 1.4 & 97.1 & 0.7 & 2.2 & 89.3 & 9.8 & 0.9 & 93.6 & - & 6.4 & 98.4 & 0.2 & 1.4 & 87.8 & - & 12.2 & 97.3 & 1.7 & 1.0 & 99.1 & 0.7 & 0.2 \\
\hline Germany & 59.2 & 5.9 & 34.9 & 88.6 & 10.2 & 1.2 & 97.6 & 1.2 & 1.2 & 93.0 & 6.6 & 0.4 & 90.5 & - & 9.5 & 96.3 & 0 & 3.7 & 74.1 & & 25.9 & 92.5 & 5.0 & 2.5 & 98.0 & 1.2 & 0.8 \\
\hline Hungary & 32.7 & 3.8 & 63.5 & 51.9 & 38.5 & 9.6 & 96.2 & 0 & 3.8 & 73.0 & 25.1 & 1.9 & 67.3 & - & 32.7 & 96.2 & 0 & 3.8 & 59.6 & & 40.4 & 98.1 & 1.9 & 0 & 100 & 0 & 0 \\
\hline Italy & 43.1 & 3.0 & 53.9 & 71.5 & 21.8 & 6.7 & 94.1 & 2.5 & 3.4 & 77.7 & 16.8 & 5.5 & 73.6 & & 26.4 & 87.5 & 0.8 & 11.7 & 71.2 & & 28.8 & 97.5 & 2.5 & 0 & 97.9 & 2.1 & 0 \\
\hline Poland & 40.0 & 20.0 & 40.0 & 86.7 & 10.0 & 3.3 & 97.8 & 1.1 & 1.1 & 81.1 & 16.7 & 2.2 & 84.4 & - & 15.6 & 93.4 & 0 & 6.6 & 80.0 & & 20.0 & 92.3 & 3.3 & 4.4 & 98.9 & 1.1 & 0 \\
\hline Russia & 42.0 & 14.6 & 43.4 & 83.1 & 13.0 & 3.9 & 97.2 & 1.4 & 1.4 & 85.7 & 11.0 & 3.3 & 82.8 & - & 17.2 & 86.4 & 0.7 & 12.9 & 69.4 & & 30.6 & 94.7 & 4.0 & 1.3 & 99.4 & 0.3 & 0.3 \\
\hline Spain & 35.3 & 4.7 & 60.0 & 80.9 & 14.9 & 4.2 & 94.1 & 1.7 & 4.2 & 78.6 & 19.4 & 2.0 & 73.4 & & 26.6 & 89.3 & 0 & 10.7 & 66.2 & & 33.8 & 94.1 & 3.7 & 2.2 & 97.2 & 1.6 & 1.2 \\
\hline $\begin{array}{l}\text { The } \\
\text { Netherlan } \\
\text { ds }\end{array}$ & 65.5 & 6.9 & 27.6 & 82.8 & 13.8 & 3.4 & 96.6 & 0 & 3.4 & 89.7 & 10.3 & 0 & 93.1 & - & & 96.6 & 0 & 3.4 & 79.3 & - & 20.7 & 100 & 0 & 0 & 100 & 0 & 0 \\
\hline
\end{tabular}


AMP, ampicillin; AMC, amoxicillin/clavulanic acid; MEC, mecillinam; CFX, cefuroxime; NAL, nalidixic acid; CIP, ciprofloxacin; SXT, trimethoprim/sulfamethoxazole; NIT, nitrofurantoin; FOS, fosfomycin; S, susceptible; I, intermediate; R, resistant.

${ }^{\text {a }}$ Minimal inhibitory concentration (MIC) value for intermediate category does not exist. 


\section{Table 4}

Antimicrobial susceptibility of Escherichia coli isolated from recurrent and not-recurrent urinary tract infection (UTI)

\begin{tabular}{|c|c|c|c|c|c|c|}
\hline \multirow[t]{3}{*}{ Antimicrobial agent } & \multicolumn{6}{|c|}{$\%$ (no. of isolates) } \\
\hline & \multicolumn{3}{|c|}{ Not-recurrent UTI $(n=2062)$} & \multicolumn{3}{|c|}{ Recurrent UTI $(n=253)$} \\
\hline & S & I & $\mathrm{R}$ & $\mathrm{S}$ & l & $\mathrm{R}$ \\
\hline Ampicillin & $45.9(947)$ & $6.4(131)$ & $47.7(984)$ & $38.7(98)$ & $8.7(22)$ & $52.6(133)$ \\
\hline AMC & $82.6(1703)$ & $13.9(286)$ & $3.5(73)$ & $81.8(207)$ & $11.9(30)$ & $6.3(16)$ \\
\hline Mecillinam & $95.6(1969)$ & $1.6(32)$ & $2.9(59)$ & $97.2(246)$ & $0.8(2)$ & $2.0(5)$ \\
\hline Cefuroxime & $82.8(1708)$ & $15.2(313)$ & $2.0(41)$ & $78.7(199)$ & $15.8(40)$ & $5.5(14)$ \\
\hline Nalidixic acid & $82.5(1701)$ & $-{ }^{a}$ & $17.5(361)$ & $72.7(184)$ & 0 & $27.3(69)$ \\
\hline Ciprofloxacin & $92.8(1910)$ & $0.2(5)$ & $7.0(144)$ & $83.0(210)$ & 0 & $17.0(43)$ \\
\hline SXT & $71.2(1468)$ & $-{ }^{a}$ & $28.8(593)$ & $65.2(165)$ & $-{ }^{a}$ & $34.8(88)$ \\
\hline Nitrofurantoin & $95.3(1965)$ & $3.1(64)$ & $1.6(33)$ & $94.9(240)$ & $3.2(8)$ & $2.0(5)$ \\
\hline Fosfomycin & $98.0(2021)$ & $1.4(29)$ & $0.6(12)$ & $99.2(251)$ & $0.4(1)$ & $0.4(1)$ \\
\hline
\end{tabular}

S, susceptible; I, intermediate; R, resistant; AMC, amoxicillin/clavulanic acid; SXT, trimethoprim/sulfamethoxazole.

${ }^{\text {a }}$ Minimal inhibitory concentration (MIC) value for intermediate category does not exist. 


\section{Table 5}

Susceptibility patterns of the most common uropathogens other than Escherichia coli

\begin{tabular}{|c|c|c|c|c|c|c|}
\hline \multirow[t]{3}{*}{ Antimicrobial agent } & \multicolumn{6}{|c|}{ Susceptibility (\%) } \\
\hline & \multicolumn{2}{|c|}{ Klebsiella pneumoniae $(n=107)$} & \multicolumn{2}{|c|}{ Proteus mirabilis $(n=104)$} & \multicolumn{2}{|c|}{ Staphylococcus saprophyticus $(n=108)$} \\
\hline & I & $\mathrm{R}$ & I & $\mathrm{R}$ & I & $\mathrm{R}$ \\
\hline Ampicillin & 0.9 & 99.1 & 0 & 32.7 & $-{ }^{b}$ & 36.4 \\
\hline AMC & 6.5 & 2.8 & 3.8 & 1.9 & 0 & 0 \\
\hline Mecillinam $^{a}$ & 2.8 & 8.4 & 4.8 & 5.8 & $-{ }^{c}$ & $-{ }^{c}$ \\
\hline Cefuroxime & 14.9 & 6.5 & 1.9 & 4.8 & 1.9 & 1.9 \\
\hline Nalidixic acid & 0 & 17.8 & 0 & 21.2 & $-{ }^{c}$ & $-{ }^{c}$ \\
\hline Ciprofloxacin & 0.9 & 4.7 & 2.9 & 6.7 & 0 & 0.9 \\
\hline SXT & $-{ }^{b}$ & 23.3 & $-{ }^{b}$ & 37.5 & $-{ }^{b}$ & 10.2 \\
\hline Nitrofurantoin & 44.9 & 37.4 & 57.7 & 42.3 & 0.9 & 0.9 \\
\hline Fosfomycin $^{a}$ & 6.5 & 5.6 & 3.9 & 9.7 & $-{ }^{c}$ & $-{ }^{c}$ \\
\hline
\end{tabular}

I, intermediate; R, resistant; AMC, amoxicillin/clavulanic acid; SXT, trimethoprim/sulfamethoxazole; MIC, minimal inhibitory concentration.

${ }^{a}$ Clinical and Laboratory Standards Institute breakpoints for $E$. coli have also been used for K. pneumoniae and $P$. mirabilis.

${ }^{\mathrm{b}}$ MIC value for intermediate category does not exist.

${ }^{\mathrm{c}}$ MIC breakpoints for this antimicrobial agent against this pathogen does not exist. 